\title{
Dimethyl ether (DME) as potential environmental friendly fuel
}

\author{
Patrycja Makoś ${ }^{1, *}$, Edyta Słupek ${ }^{1}$, Joanna Sobczak ${ }^{1}$, Dawid Zabrocki ${ }^{1}$, Jan Hupka ${ }^{1}$, \\ and Andrzej Rogala ${ }^{1}$ \\ ${ }^{1}$ Gdansk University of Technology, Faculty of Chemistry, Department of Process Engineering and \\ Chemical Technology, ul. G. Narutowicza 11/12, 80-233 Gdansk, Poland
}

\begin{abstract}
In recent years, there has been a growing interest in replacing petroleum fuels with so-called second generation environmental friendly fuels. Compared to traditional petroleum fuels dimethyl ether (DME) could be used as a clean high-efficiency compression ignition fuel with reduced particulate matter $(\mathrm{PM})$, sulfur oxides $\left(\mathrm{SO}_{\mathrm{x}}\right)$, hydrocarbons $(\mathrm{HC})$, carbon monoxide $(\mathrm{CO})$ as well as combustion noise. Compared to some of the other leading alternative fuel candidates i.e., methane, methanol, ethanol, compressed natural gas, DME appears to have the largest potential impact on society including well-to-wheel greenhouse gas emissions, non-petroleum feedstocks, well-to-wheel efficiencies, fuel versatility, infrastructure, availability, economics, and safety and should be considered as the fuel of choice for eliminating the dependency on petroleum. This paper reviews the properties and the DME combustion effects on environmental and they were compared to diesel characteristic as well as the effect of blending DME with liquefied petroleum gas (LPG), conventional diesel fuel and biodiesel were discussed.
\end{abstract}

\section{Introduction}

Nowadays, internal combustion engines are one of the main source of environmental pollution. It is estimated that about $30 \%$ of air pollution arises from automobile emission [1]. A similar problem is also observed in the case of sea transport [2]. In 2007, $\mathrm{CO}_{2}$ emissions from ships were $3.3 \%$ of global human-made. However, the International Maritime Organization (IMO) estimates that emission of $\mathrm{CO}_{2}$ increase by as much as 72 percent by 2020 . In addition, IMO expects that nitrogen oxides (NOx) and particulate matter $\left(\mathrm{PM}_{2.5}\right)$ emissions from ships will amount to 2.1 million tons a year and 170,000 tons a year respectively [3]. Furthermore, the combustion of the most popular petroleum fuels causes also the emission of other dangerous pollutants, i.e. carbon oxide (CO), sulfur oxides $\left(\mathrm{SO}_{\mathrm{x}}\right)$ and hydrocarbons $(\mathrm{HC})$ [4]. These emissions harm human as well as animal populations. In addition, the US Environmental Pollution Administration (EPA) demonstrated that the air pollutants from maritime shipping are transported over long distances which contributes to the deterioration of air quality in much larger areas even hundreds of miles Island [3]. That is why in recent years many rigorous regulations for

\footnotetext{
*Corresponding author: patrycja.makos@pg.edu.pl
} 
reducing the emissions of greenhouse gases have been introduced [5]. At present, most petroleum-derived fuels including mainly marine fuel oil, marine diesel oil, marine gasoline oil, and, recently, liquefied natural gas are used in both international and domestic maritime transport. However, in order to reduce the emission of harmful substances into the atmosphere, one solution is to use alternative, environmentally friendly fuels. The definition of alternative fuels includes methanol, ethanol [6-8], hydrogen, compressed natural gas, liquefied petroleum gas (LPG), vegetable oils and fatty acid methyl esters [9], dimethyl ether (DME) [7] and blends of these with gasoline or diesel [7]. Among alternative fuels, dimethyl ether offers excellent promise as an environmentally friendly fuel with lower $\mathrm{CO}, \mathrm{HC}, \mathrm{NOx}$ emission and almost smoke-free combustion and it may lessen the destruction of the ozone layer and global warming because of characteristics of good resolvability in the atmosphere.

\section{Dimethyl ether}

The first studies on dimethyl ether combustion and emissions were reported in 1995 but the first pure DME operated engine was developed two years later $[10,11]$. Due to the positive effects of research, DME as an alternative fuel has recently been an object of considerable interest among the scientists which is illustrated by the number of relevant papers published between 1995 and 2019 (Fig. 1).

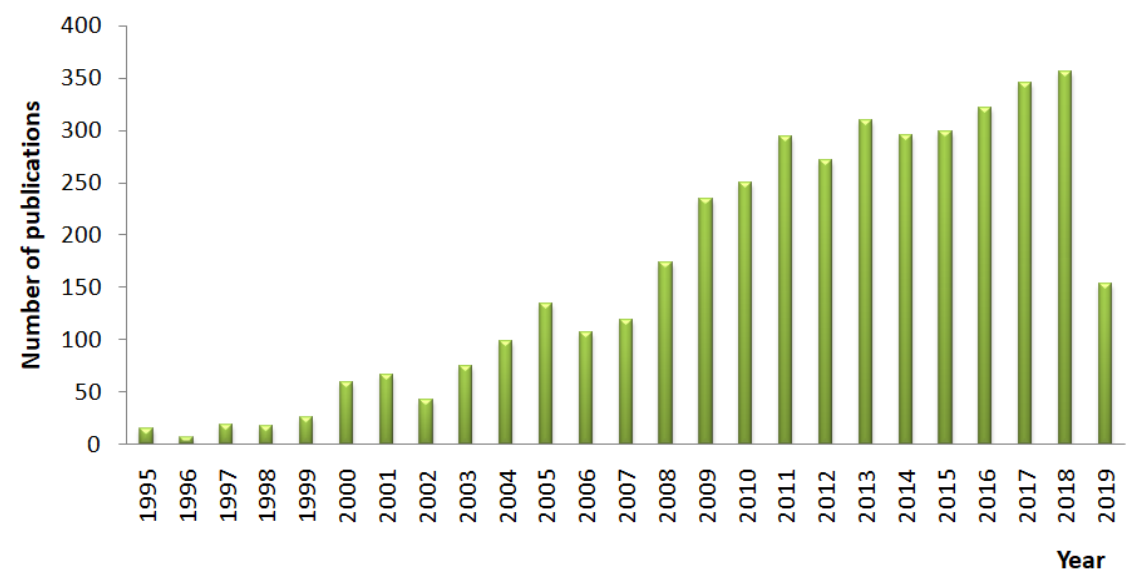

Fig. 1. Number of papers published during 1995-2019 on the presence of application of DME as an alternative fuel - based on Scopus database (searched keywords: dimethyl ether, fuel; accessed on 04.05.2019).

\subsection{Physicochemical properties of DME}

DME is a liquefied gas with handling characteristics similar to those of LPG [12]. Therefore, DME requires the same conditions of use and storage considerations as for LPG. Dimethyl ether is a synthetic fuel, for which production raw materials such as natural gas, coal, residual oil, crude oil, biomass or waste products can be used. The possibility of the DME production using the biomass or waste products makes this fuel very ecological. Under the atmospheric conditions of $0.1 \mathrm{MPa}$ and $298 \mathrm{~K}$, DME exists as an invisible ether compound in gaseous phase and transitions from vapor to liquid phase when vapor phase DME is pressurized above $0.5 \mathrm{MPa}$ at standard atmospheric temperature $[13,14]$. DME has 
a low carbon-to-hydrogen ratio $(\mathrm{C}: \mathrm{H})$ with a chemical formula of $\mathrm{CH}_{3}-\mathrm{O}-\mathrm{CH}_{3}$. DME has higher oxygen content than other fossil fuels (34.8\%) and has no direct $\mathrm{C}-\mathrm{C}$ bond. The $\mathrm{C}-\mathrm{O}$ bond energy is lower than the $\mathrm{C}-\mathrm{H}$ bond energy $[15,15]$. Therefore, $\mathrm{C}-\mathrm{O}$ bonds in DME break more easily than the $\mathrm{C}-\mathrm{H}$ bonds [17]. The lower bond energy of $\mathrm{C}-\mathrm{O}$ bonds than $\mathrm{C}-\mathrm{H}$ bonds results in a shorter ignition delay and higher cetane number when DME is used as a fuel compared to other fuel types. The bond energies of $\mathrm{C}-\mathrm{H}$ and $\mathrm{C}-\mathrm{O}$ in $\mathrm{DME}$ are $410.4 \mathrm{~kJ} / \mathrm{mol}$ and $359.0 \mathrm{~kJ} / \mathrm{mol}$, respectively. DME is much less viscous and lubricating than diesel. Gaseous DME is denser than dry air while the density of liquid DME is $668 \mathrm{~kg} / \mathrm{m}^{3}$ at normal temperature and pressure [18]. Liquid density of DME is two thirds that of water and DME dissolves in water up to $6 \%$ by mass [19]. DME differs significantly from conventional diesel in terms of its fuel density and viscosity characteristics. Low density and viscosity of DME results in the leakage from fuel storage tanks, and the fuel supply system from the fuel tank to the injection system in engines. Physical and chemical properties of DME and diesel are listed in Table 1.

Table 1. Comparison of DME and diesel properties.

\begin{tabular}{|c|c|c|}
\hline Properties & DME & Diesel fuel \\
\hline Chemical formula & $\mathrm{CH}_{3}-\mathrm{O}-\mathrm{CH}_{3}$ & - \\
\hline Molar mass [g/mol] & 46 & 170 \\
\hline Oxygencontent [\% w/w] & 34.8 & 0 \\
\hline Carbon-to-hydrogen ratio & 0.337 & 0.516 \\
\hline Cetanenumber & $55-66$ & $40-50$ \\
\hline Low calorific number [MJ/kg] & 27.600 & 42.5 \\
\hline Viscosity [cP] & 0.15 & 2 \\
\hline Density [kg/m ${ }^{3}$ ] & 660 & 831 \\
\hline Auto-ignitiontemperature [K] & 508 & 523 \\
\hline Boiling point [K] & 248.1 & $450-643$ \\
\hline Stoichiometric air-fuel mass ratio & 8.9 & 14.6 \\
\hline
\end{tabular}

However, there are also disadvantages of using DME as a substitute for diesel. DME is characterized by lower viscosity compared to diesel fuel, which can lead to leakage and wear of parts. In addition, DME has a lower heating value $(28.8 \mathrm{~kJ} / \mathrm{kg})$ compared to diesel $(42.5 \mathrm{~kJ} / \mathrm{kg})$, and despite better energy efficiency using DME still requires a little more fuel injected per cycle [15]. The main advantages and disadvantages of DME are shown in Table 2.

Table 2. Comparison of DME and diesel properties. Advantages and disadvantages of application DME as a fuel.

\begin{tabular}{|c|c|}
\hline Advantages & Disadvantages \\
\hline $\begin{array}{c}\text { High oxygen content - smokeless } \\
\text { combustion }\end{array}$ & Low combustion enthalpy \\
\hline $\begin{array}{c}\text { Low boiling point - quick evaporation when } \\
\text { a liquid-phase DME spray is injected into the } \\
\text { engine cylinder. }\end{array}$ & $\begin{array}{c}\text { Low viscosity - could provide to dysfunction } \\
\text { of the conventional film bearing between the } \\
\text { Needles and sleeve of the injector, and this } \\
\text { will cause leakage and wear and tear of parts }\end{array}$ \\
\hline High cetane number - good fuel for auto ignition & Lowmodulus of elasticity \\
\hline Can achieve ultra-low emissions & $\begin{array}{c}\text { Low boiling point - requires the use of } \\
\text { a pressurized system to maintain the fuel in } \\
\text { liquid state }\end{array}$ \\
\hline Better energy efficiency & Low energy content - large fuel tanks \\
\hline Lower exhaustgasreactivity & \\
\hline Multi-source and multipurpose \\
fuel
\end{tabular}




\section{Environmental benefits of using DME as fuel}

\subsection{DME fuel}

\subsection{1 $\mathrm{NO}_{\mathrm{x}}$ emission}

The degree of emissions of DME - fueled fuel systems depends primarily on the specification of the engine, the fuel supply system as well as the engine's operating conditions, including the injection strategy. Currently, there are several probable causes for lower $\mathrm{NO}_{\mathrm{x}}$ emissions when DME fuels are combusted compared to conventional fuel used in ships - diesel. In several publications, the reason for NOx emission reduction was the fact that DME has a high cetane number, a lower heating value and a higher latent heat capacity than diesel [20-21]. However, in other works it was found that the reason is a short ignition delay, which leads to a small amount of pre-mixed burned DME and low peak combustion temperature [23, 24]. In another study, the authors found that DME combustion may have lower NOx emissions than diesel fuel combustion under the same diffusion time conditions, although DME emit higher $\mathrm{NO}_{\mathrm{x}}$ emissions at the same heat release rate [25]. However, there are also papers where it has been proven that the $\mathrm{NO}_{\mathrm{x}}$ emission is higher when using DME fuel compared to diesel due to the short ignition delay under the same energy input conditions [19, 26-28].

\subsubsection{PM emission}

It is well known that soot is formed in fuel-rich regions under high equivalence ratio and high temperature conditions $(1500-2500 \mathrm{~K})$. In the region rich in fuel, acetylene $\left(\mathrm{C}_{2} \mathrm{H}_{2}\right)$ is formed by the decomposition of long-chain alkanes of diesel oil [20]. The emerging acetylene is one of the precursors to the formation of soot. Soot precursors also include unsaturated hydrocarbons, including ethylene $\left(\mathrm{C}_{2} \mathrm{H}_{4}\right)$ and 2-propynyl $\left(\mathrm{C}_{3} \mathrm{H}_{3}\right)$ [29]. Their amount decreases with increasing oxygen content in the fuel molecule and with decreasing direct carbon-to-carbon bonds [29]. Therefore, when burning DME, compounds such as acetylene are not easily formed, because DME contains $34.8 \% \mathrm{w} / \mathrm{w}$ oxygen, and also does not have direct $\mathrm{C}-\mathrm{C}$ bonds $[24,30,31]$. In addition, it has been proven that the oxygen content in the molecule suppresses the formation of soot in the DME combustion process $[32,33]$. DME produces much lower solids $(0.026 \%)$ compared to other fuels under high pressure diesel conditions, such as diesel $(0.51 \%)$, biodiesel $(0.52 \%)$ and compressed natural gas $(0.30 \%)$. It has also been proven that a DME-driven engine contains in the higher combustion (71\%) a soluble organic fraction than in diesel $(20 \%)$ of total carbon [34]. Sometimes a small PM emission was observed during DME combustion, which resulted from the use of fuel additives to improve lubrication [34-35]. However, during the combustion of DME, almost zero soot emission is observed. This means that DME-fuelled engines would not need a particulate filter in the after-treatment system.

\subsubsection{CO emission}

The emission of $\mathrm{CO}$ as in the case of $\mathrm{HC}$ is caused by incomplete combustion and occurs in too rich or too lean mixing conditions [36]. The CO emission from DME combustion is lower compared to the combustion of diesel fuel. The reason for this is that DME has a low ratio of carbon atoms to hydrogen atoms in the molecule and because of the high oxygen content characteristics that facilitate good mixing and fast oxidation of intermediate species 
$[27,37,38]$. However, sometimes the higher CO emissions associated with DME in compare with a diesel could result from the longer injection duration, coupled with lower injection pressures and larger spray holes. In these cases, the interaction between fuel-injection system behavior and the combustion chamber design should be optimized to minimize $\mathrm{CO}$ emissions. Because $\mathrm{CHO}$ and $\mathrm{CH}_{2} \mathrm{O}$ are produced during the combustion of $\mathrm{DME}$, depending on the reaction process, an also larger amount of $\mathrm{CO}$ may be produced. In the case of $\mathrm{CO}$ emission increase, it could nevertheless be used in the after-treatment system [39].

\subsubsection{HC emission}

$\mathrm{HC}$ emissions from DME combustion are usually lower than or equal to emissions from diesel fuel combustion. It is caused by partial or unburned under fuel in fuel-rich conditions or incomplete fuel-air mixing [40]. Combustion DME results in lower HC emissions than diesel fuel combustion because DME has a high cetane number, as well as good evaporation, atomization and mixing characteristics, which causes the DME ignition delay to be shorter compared to diesel. This makes the formation of over-rich or over-lean regions mixture regions resulting in significantly reduced $\mathrm{HC}$ emissions [24, 41-43]. In addition, the presence of oxygen in the DME molecule contributes to relatively smaller fuel regions compared to diesel, which also reduces $\mathrm{HC}$ emissions. another reason for $\mathrm{HC}$ emissions during DME combustion is quenching due to impingement of the injected fuel spray on the cold engine-cylinder wall. HC emission due to wall-wetting is reduced during DME combustion because DME spray has a shorter spray tip penetration, and faster evaporation characteristics than diesel spray [27, 41].

\subsubsection{Combustion noise}

Due to the fact that the ignition delay is shorter in the case of DME compared to diesel, the increase in pressure for DME during the pre-mixing step is slower than in the case of diesel, which reduces the combustion noise [44].

\subsection{DME blended LPG}

The blending of DME and LPG has several technological advantages i.e.

- LPG infrastructure can be used to supply DME for DME-fueled vehicles,

- compensation for the low cetane number of LPG and the low energy density of DME,

- fuel consumption in DME-fueled engines is improved by LPG blend [45].

The mixture of DME and LPG demonstrated lower $\mathrm{NO}_{x}, \mathrm{PM}$ and $\mathrm{CO}$ emissions compared to diesel fuel. In addition, under medium and high engine load conditions DME/LPG blends showed lower HC emission, because of fast evaporation as well as good mixing of air and fuel. However, under low load conditions the HC emissions can increase due to increase in ignition delay [46]. Therefore, prior to use DME/LPG blends as a fuel the optimal blending ratio and engine operating conditions of DME and LPG mixture should be determined, because excessive blending of LPG can deteriorate the combustion stability and the emission of $\mathrm{HC}$. 


\subsection{DME blended diesel}

The fuel mixture of DME and diesel which contained from 10 to $30 \%$ of diesel fuel significantly reduced emissions of PM due to the increase in oxygen content and decrease in $\mathrm{C} / \mathrm{H}$ ratio and aromatic fraction. Emission of $\mathrm{NO}_{\mathrm{x}}$ from blends of DME and diesel are generally lower than those of diesel because of the decrease in in-cylinder temperature by the premixed combustion amount. However, the emissions of $\mathrm{HC}$ and $\mathrm{CO}$ are higher from DME/diesel blends than diesel alone. The HC emission increases with the addition of DME, due to the high latent heat of vaporization and high oxygen content of DME created an over-lean mixture region, where HC formed [47-49]. Lower concentration of DME in DME/diesel blends (less than 10\%) did not have significantly different HC emission characteristics to those of diesel alone [50]. DME content above $40 \%$ caused an increase in $\mathrm{HC}$ emissions and a decrease in smoke emission [51].

\subsection{DME blended biodiesel}

The main technological benefit application of DME/biodiesel blends is an improvement of lubrication due to the high viscosity and lubrication characteristics of biodiesel which compensates the low viscosity and lubrication characteristics of DME [52]. The fuel mixture of palm methyl ester and DME indicated lower smoke emission than diesel because both biodiesel and DME have a high oxygen content as 35\%. However, the emission of NOx was at a slightly lower level compared to diesel [9]. The DME/biodiesel blends contained up to $10 \%$ of rapeseed oil ensures reduction of NOx emissions under all engine load conditions. HC emissions from the fuel mixture of DME/biodiesel blends were similar to those from diesel under low- and medium-engine load conditions. However, hydrocarbons emissions from DME/rapeseed oil blends were lower than those of diesel at high engine loads regardless of blending ratio. CO emission from DME/biodiesel blend was higher than that of diesel, but tended to decrease with an increase in the biodiesel fraction due to the increase in oxygen content. When DME was added as an additive to the emulsified fuel (50\% diesel : 50\% ethanol), nitrogen oxides and ignition delay were significantly decreased. Fuel efficiency has been increased and emission of pollutants has been reduced [8].

\section{Conclusions}

Dimethyl ether has the appearance of an excellent, environmental-friendly, efficient alternative fuel for use in a diesel engine. Unlike conventional diesel which is produced from non-renewable crude oil, DME can be produced anywhere using renewable products like municipal waste, biomass (forest products and animal waste), pulp and paper waste, coal etc. The advantages of DME over conventional diesel include decreased emissions of nitro gen oxides, hydrocarbons, particulate matter and carbon monoxide. Further, using DME as a fuel a significant combustion noise reduction is obtained. DME can also be used as an additive to conventional petroleum fuels as well to biodiesel. The addition of DME to another type of fuel under optimal conditions also shows a significant reduction in the emission of harmful compounds into the atmosphere, compared to petroleum fuels.

The author gratefully acknowledge the financial support from the National Interreg Southbaltic Region Programme - decision No. STHB.02.02.00-22-0092/16. 


\section{References}

1. R. Senthil, K.Arunan, R.Silambarasan, G.Pranesh, P. Mebin Samuel, IJAER 10, 29345 (2015)

2. N. Altunbulak, Transport. Secur. Against Terrorism 54, 75 (2009)

3. https://www.azocleantech.com/article.aspx?ArticleID=714 (accessed: 07.01.2019)

4. Q. Z. Jiang, Y. M. Xu, W. J. Xin, Z. Z. Song, Q. Q. Song, Petro. Sci. 9, 558 (2012)

5. A. T. Lv, C. B. Zhang, A. H. Shi, J. Transport Informat. Saf. 27, 52 (2009)

6. EEA Technical report, No. 4/2013, https://www.eea.europa.eu/publications/the-impactof-international-shipping/file (accesed: 07.01.2019)

7. H. J. Kim, H. K. Suh, S. H. Park, C. S. Lee, Energy Fuels 22, 2091 (2008)

8. M. P. Ashok, Energy Fuels 25, 3799 (2011)

9. Y. Wang, L. Zhou, Energy Fuel 21, 1454 (2007)

10. W. Ying, Z. Longbao, Appl. Therm. Eng. 28, 1589 (2008)

11. J. D. Forum, DME Handbook (Ohmsha Ltd., 2007)

12. R. P. Verbeek, A. Van Doom, M. van Walwijk (96.OR.VM.029. 1/RV, TNO Road-Vehicles Research Institute, 1996)

13. S. H. Park, C. S. Lee. Prog. Energy Combust. Sci. 39, 147 (2013)

14. G. Thomas, B. Feng, A. Veeraragavan, M. J. Cleary, N. Drinan, Fuel Proc. Technol. 119, 286 (2014)

15. C. Arcoumanis, C. Bae, R. Crookes, E. Kinoshita, Fuel 87, 1014 (2008)

16. C. K. Law, Combustion physics (Cambridge University Press, 2006)

17. W. M. Haynes, CRC handbook of chemistry and physics 2011-2012 (CRC Press/Taylor \& Francis, 2012)

18. I. Sezer, Int. J. Therm. Sci. 50, 1594 (2011)

19. M. Oguma, G. Hyun, S. Goto, M. Konno, S. Kajitani, SAE Tech. Paper 1, 1711 (2002)

20. Z. Zhu, D. K. Li, J. Liu, Y. J. Wei, S. H. Liu, Appl. Therm. Eng. 35, 9 (2012)

21. A. Saeed, K. Saeed, A. Ahmed, K. A. Malik, SAE Tech. Paper 1, 51 (2006)

22. L. Xinling, H. Zhen, Sci. Total Environ. 407, 2234 (2009)

23. R. Egnell, SAE Tech. Paper 1, 651 (2001)

24. H. Teng, J. C. McCandless, J. B. Schneyer, SAE Tech. Paper 1, 154 (2001)

25. M. Konno, S. Kajitani, M. Oguma, T. Iwase, K. Shima, SAE Tech. Paper 1, 1116 (1999)

26. S. Kajitani, Z. Chen, M. Konno, K. Rhee, SAE Tech. Paper 1, 972 (1997)

27. M. Y. Kim, S. H. Yoon, B. W. Ryu, C. S. Lee, Fuel 87, 2779 (2008)

28. M. Alam, O. Fujita, K. Ito, S. Kajitani, M. Oguma, H. Machida, SAE Tech. Paper 1, 3599 (1999)

29. C. K. Westbrook, DOE report (1999) 
30. H. Teng, J.C. McCandless, J. B. Schneyer, SAE Tech. Paper 1, 759 (2003)

31. H. J. Curran, W. J. Pitz, C. K. Westbrook, Symp. Combust. 27, 379 (1998)

32. H. Miyamoto, H. Ogawa, T. Arima, K. Miyakawa, SAE Tech. Paper 1, 962115 (1996)

33. H. J. Curran, E. M. Fisher, P. A. Glaude, N. M. Marinov, W. J. Pitz, C. K. Westbrook, SAE Tech. Paper 1, 0653 (2001)

34. S. Sukh, J. Graham, R. Striebich, Chemosphere 42, 681 (2001)

35. H. Jung, D. B. Kittelson, M. R. Zachariah, SAE Tech. Paper 1, 3179 (2003)

36. J. B. Heywood, McGraw-Hill Press, New York (1998)

37. Y. Wang, Y. Zhao, F. Xiao, D. Li, Energy Convers. Manage. 77, 52 (2014)

38. M. Y. Kim, J. H. Lee, C. S. Lee, Energy Fuel 22, 4206 (2008)

39. H. Ofner, D. W. Gill, C. Krotscheck, SAE Tech. Paper 1, 981158 (1998)

40. T. Fleisch, C. McCarthy, A. Basu, C. Udovich, P. Charbonneau, W. Slodowske, SAE Tech. Paper 1, 950061 (1995)

41. S. H. Park, H. J. Kim, C. S. Lee, Energy Fuel 25, 1772 (2011)

42. H. Ogawa, N. Miyamoto, M. Yagi, SAE Trans. J. Fuel Lubr. 112, 2413 (2003)

43. M. Oguma, H. Shiotani, S. Goto, S. Suzuki, SAE Paper 1, 2202 (2005)

44. T. H. Fleisch, C. Meurer, (In: AVL conference engine and environment, 1995)

45. S. H. Park, C. S. Lee, Energy Convers. Manag. 86, 848 (2014)

46. S. Lee, S. Oh, Y. Choi, K. Kang, Appl. Therm. Eng. 31, 1929 (2011)

47. W. Ying, L. Genbao, Z. Wei, Z. Longbao, Fuel Proc. Technol. 89, 1272 (2008)

48. W. Ying, Z. Longbao, W. Hewu, Atmos. Environ. 40, 2313 (2006)

49. E. M. Chapman, A. L. Boehman, P. Tijm, F. Waller, SAE Tech. Paper 1, 3626 (2001)

50. C. L. Chen, S. Kajitan, K. Minegishi, M. Oguma, SAE Tech. Paper 1, 982538 (1998)

51. M. Ikeda, M. Mikami, N. Kojima, SAE Tech. Paper 1, 2006 (2000)

52. T. Okamoto, T. Nakasato, M. Konno, SAE Tech. Paper 1, 2016 (2007) 